\title{
A study on clinico etiological spectrum of intestinal obstruction in paediatric age group
}

\author{
M. Amin Memon, Jiwan Lal Patel, Ram Kumar Siddharth, Mahendra Kumar Dhuware*
}

Department of Paediatric Surgery, Pt. JNM Medical College, Raipur, Chhattisgarh, India

Received: 04 July 2016

Accepted: 08 July 2016

\section{*Correspondence:}

Dr. Mahendra kumar Dhuware,

E-mail: drmahendradhuware@gmail.com

Copyright: (C) the author(s), publisher and licensee Medip Academy. This is an open-access article distributed under the terms of the Creative Commons Attribution Non-Commercial License, which permits unrestricted non-commercial use, distribution, and reproduction in any medium, provided the original work is properly cited.

\begin{abstract}
Background: Acute intestinal obstruction is very common surgical emergencies in paediatric age. There are many surgical causes for morbidity and mortality in paediatric age group of which intestinal obstruction giving large contribution. In most of studies child survival after surgical procedures for intestinal obstruction was good while the death rates were more when there was delay in presentation, and management. Morbidity, complications and mortalities are more severe when presented late. There is a delay in the initial presentation of intestinal obstruction cases due to various reasons.

Methods: Present study enrolled all the patients presenting with signs and symptoms of intestinal obstruction in Paediatric surgery unit of Dept. of surgery of Dr. BRAM Hospital, Raipur (C.G.), India during January 2014 to August 2015. Patients with intestinal obstruction were admitted in paediatric surgery ward with provisional diagnosis of acute intestinal obstruction. Immediately after admission, conservative management started till the hydration and urine output becomes normal. Routine and specific investigations were done. As the study includes most of cases of acute dynamic intestinal obstruction most of cases after initial resuscitation were managed by appropriate procedures. Postoperative care was done and outcome of the study was noted.

Results: Maximum cases of intestinal obstruction were in neonatal period and least in 5-14 years. Sex ratio is 2.5:1 (male to female). ARM was the major cause of obstruction in neonatal $(<1$ month) age group. IHPS and Hirschsprung's disease were most common cause of GI obstruction in 1 month to 1 year age group in our study. 4 of our cases did not have accurate diagnosis and were responded well to conservative management. Most of the patients presented with complain of not passing stool followed by distension of abdomen. $85.94 \%$ of cases are congenital in our study. Large gut portion was involved in majority of cases. Overall survival rate was $91.40 \%$.

Conclusions: Present study concludes that congenital causes are more common in paediatric intestinal obstruction cases. Early diagnosis and intervention are crucial factors to improve the outcome.
\end{abstract}

Keywords: Intestinal obstruction, Pediatric age, Etiology

\section{INTRODUCTION}

Acute intestinal obstruction is very common surgical emergency in paediatric age. There are many surgical causes for morbidity and mortality in paediatric age group of which intestinal obstruction giving large contribution. In paediatric patients cause of intestinal obstruction varies with the age of patient.
In most of studies child survival after surgical procedures for intestinal obstruction was good while the death rates were more when there was delay in presentation, and management. Morbidity, complications and mortalities are more severe when presented late. ${ }^{1,2}$ Abdomen is like a magic box, because any case admitted in the surgical ward as acute abdomen is dilemma to operating surgeon unless the box is opened. 
Mechanical intestinal obstruction of varied etiology constitutes one of the important differential diagnoses of such acute abdomen. The diagnosis and management of intestinal obstruction requires both clinical and surgical acumen.

Many of these etiologies are congenital in origin and need staged repair with good functional outcome. Diagnosis of etiology and management of obstruction require both clinical and surgical expertise along with the judicious use of various diagnostic modalities. Though the classical presentation is pain abdomen and vomiting; further investigations are required to come to a preoperative diagnosis. ${ }^{3-8}$

There is delay in the initial presentation of intestinal obstruction cases due to various reasons. Due to these delays in initial presentation patients would have been dehydrated or complications would have set in.

It is necessary to measure the present clinical status of intestinal obstruction cases. Also to quantify their causes and health care needs as they commonly present with emergency condition. There are very few studies available in study area, with the above background the present study is done to see the clinic etiological spectrum of intestinal obstruction in paediatric age group.

\section{METHODS}

Intestinal obstruction is a common condition presenting in paediatric age. Present study enrolled all the patients presenting with signs and symptoms of intestinal obstruction in Paediatric surgery unit of Dept. of surgery of Dr. BRAM Hospital, Raipur (C.G.), India during January 2014 to August 2015. Ethical approval was obtained from institutional ethical committee.

\section{Inclusion Criteria}

- All paediatric patients (birth to 14 years) who presented with signs and symptoms of congenital / acquired intestinal obstruction.

- Patients presented with intestinal perforation secondary to distal obstruction.

- Adynamic obstruction due to congenital aganglinosis (hirschsprung"s disease)

\section{Exclusion Criteria}

- Patients with perforation peritonitis without distal obstruction.

- Adynamic obstruction (Secondary to medical conditions like uremia and electrolyte imbalance etc.)
- Oesophageal obstruction (Oesophageal stenosis, oesophageal atresia and achalasia cardia, etc).

Patients with intestinal obstruction (as above mentioned inclusion and exclusion criteria) were admitted in paediatric surgery ward with provisional diagnosis of acute intestinal obstruction. Immediately after admission, resuscitation with I.V. fluids started till the hydration and urine output becomes normal. Nasogastric decompression with Ryles's tube and infant feeding tubes was carried out. Close observation of all parameters like pulse rate, blood pressure, respiratory rates, abdominal girth, bowel sounds, tenderness and guarding was done.

The following investigations are carried out - CBC ( $\mathrm{Hb}$, TLC, DLC, Platelets), Blood grouping, urine routine and microscopy, RBS, urea, creatinine, serum electrolytes in all patients.

Plain X-ray abdomen erect was done in all patients. Special X-rays - invertogram and contrast enemas were done, when required. Ultrasonography of abdominopelvis was done in most of patients for confirmation of $\mathrm{X}$ ray findings, and associated others abnormalities. Majority of cases of acute dynamic intestinal obstruction most of cases after initial resuscitation were managed by appropriate procedures.

Postoperative care was done and outcome of the study was noted (in terms of survival and death). The results are tabulated stressing the following points- aetiology, age, sex, symptoms, examination findings, investigations, operative findings, and operative procedures adopted. Data was compiled in MS Excel and checked for its completeness and correctness, and it was analyzed.

\section{RESULTS}

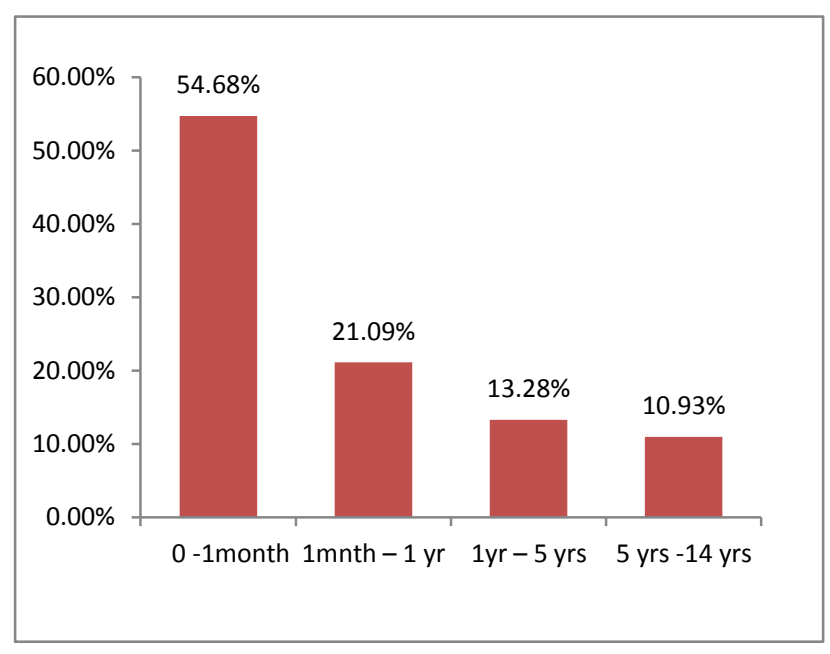

Figure 1: Age wise distribution of cases. 


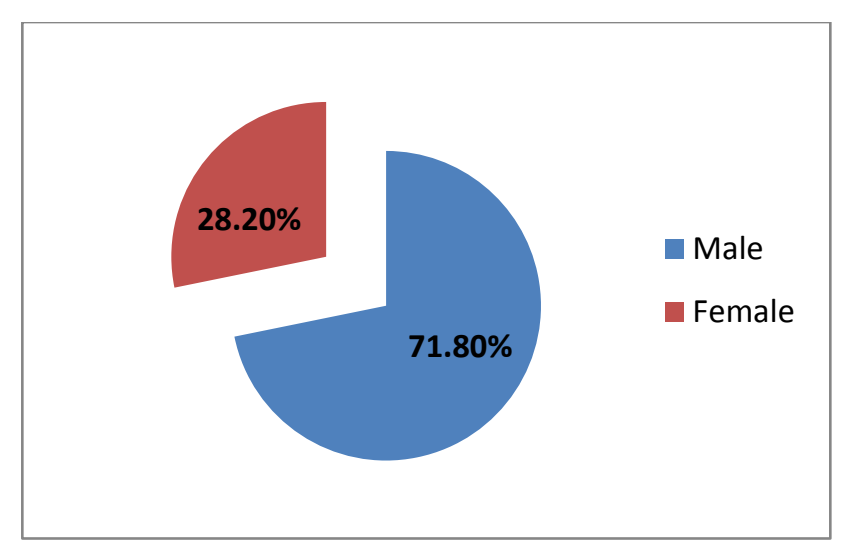

Figure 2: Gender wise distribution of study subjects.

Maximum cases of intestinal obstruction were in neonatal period and least in 5-14 years. Sex ratio is 2.5:1 (male to female) (Figure 1, 2).

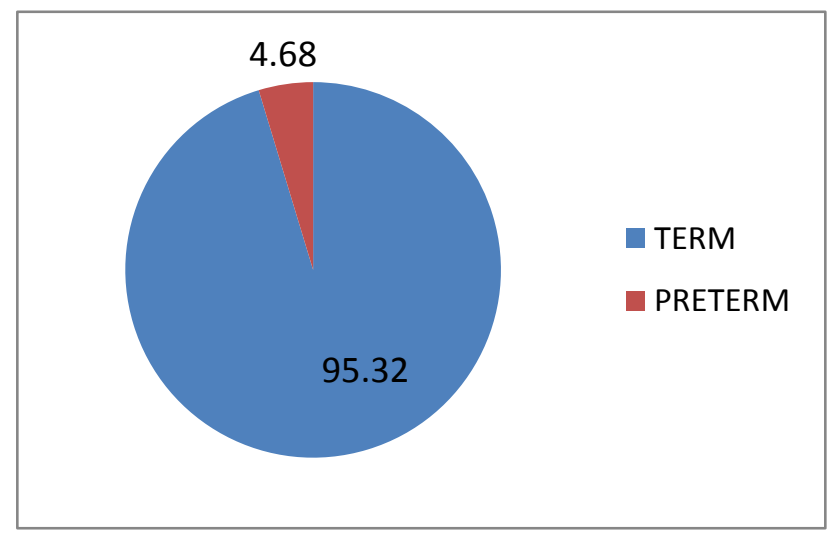

Figure 3: Distribution of study subjects according to term pregnancy $(\%)$.

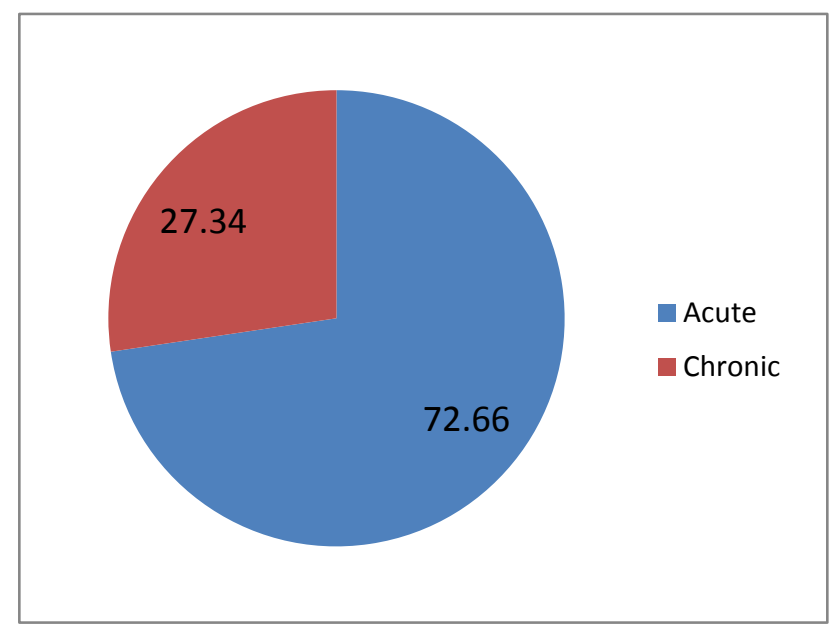

Figure 4: Distribution of study subjects according to type of presentation (\%).

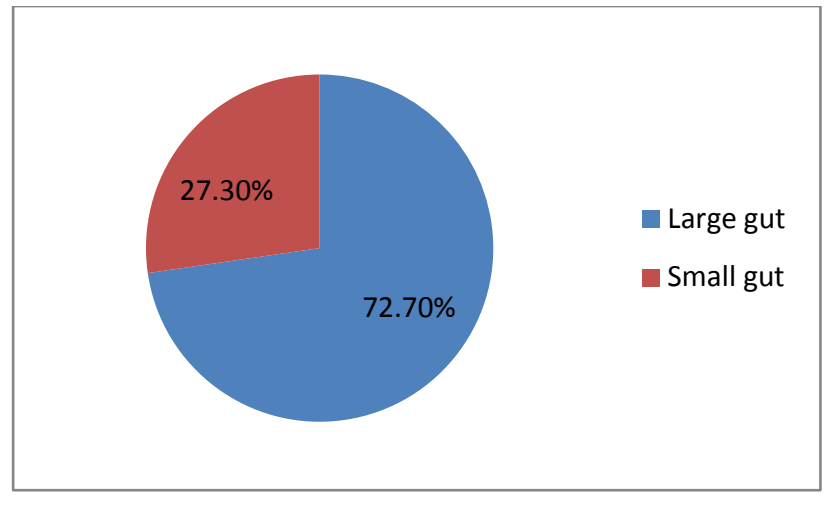

Figure 5: Proportion of involvement of intestinal segment.

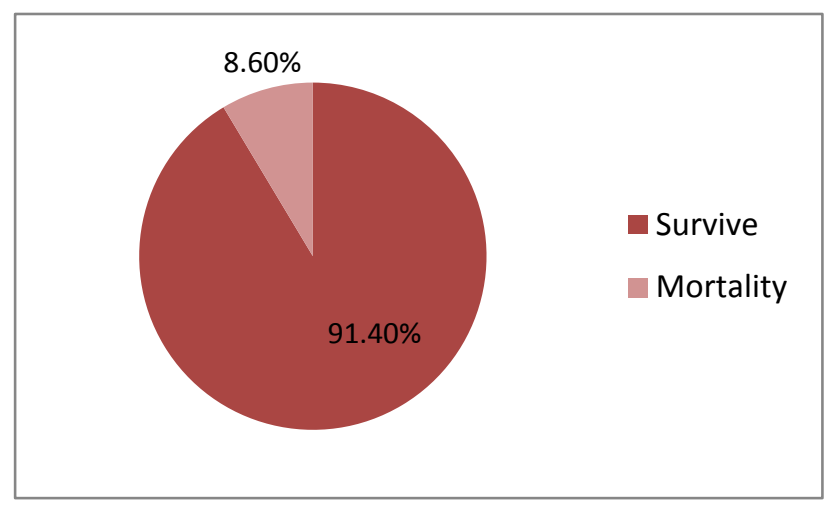

Figure 6: Distribution of subjects according to outcome.

Most common aetiology for intestinal obstruction in 0-1 month age group was ARM (81.42\%) (Table 1). IHPS and Hirschsprung's disease were most common cause of G1 obstruction in 1 month to 1 year age group in our study (Table 2). During 1-5 years also Hirschsprung's disease was most common cause of GI obstruction presenting as chronic constipation (Table 3).

4 of our cases did not have accurate diagnosis and were responded well to conservative management. Cause of obstruction must be some inflammatory pathology and flimsy adhesions (Table 4). Most of children in our study were term babies (Table 5, Figure 3). Most of the patients were delivered at home by normal vaginal delivery (Table 6). Polyhydramnios was seen in cases of GI atresia. $43.76 \%$ did not have any antenatal USG (Table 7). Not passing stool was there in most of the patients $(93.75 \%)$ followed by $116(90.63 \%)$ had distention of abdomen (Table 8). Chronic obstruction was there in $35(27.34 \%)$ cases (Table 9, Figure 4$) .85 .94 \%$ of cases were congenital in our study (Table 10). Large gut portion was involved in majority of cases. Overall survival rate was $91.40 \%$ (Figure 5,6). 
Table 1: Neonatal presentation of intestinal obstruction $(0-1$ month $)(n=77)$.

\begin{tabular}{|lllllll|}
\hline Etiology & Males & $\%(\mathbf{M})$ & Females & $\%(\mathbf{F})$ & Total & Total \% \\
\hline High ARM & 34 & 48.57 & 14 & 20 & 48 & 68.57 \\
\hline Low ARM & 7 & 10 & 2 & 2.85 & 9 & 12.85 \\
\hline Hirschprung ds & 3 & 4.28 & 1 & 1.42 & 4 & 5.7 \\
\hline Intestinal Atresia & 2 & 2.85 & 3 & 4.28 & 5 & 7.13 \\
\hline Obstructed inguinal hernia & 1 & 1.42 & 0 & 0 & 1 & 1.42 \\
\hline Meconium ileus & 1 & 1.42 & 1 & 1.42 & 2 & 2.85 \\
\hline Malrotation & 0 & 0 & 1 & 1.42 & 1 & 1.42 \\
\hline Total & 48 & 68.54 & 22 & 31.39 & 77 & 100 \\
\hline
\end{tabular}

Table 2: Presentation of intestinal obstruction in age 1 month-1 year $(n=27)$.

\begin{tabular}{|lllllll|}
\hline Etiology & Males & $\%(\mathbf{M})$ & Females & $\%(\mathbf{F})$ & Total & Total $(\%)$ \\
\hline IHPS & 6 & 22.22 & 1 & 3.7 & 7 & 25.93 \\
\hline High ARM & 0 & 0 & 2 & 7.4 & 2 & 7.4 \\
\hline Low ARM & 5 & 18.5 & 0 & 0 & 5 & 18.5 \\
\hline Hirschsprung's disease & 5 & 18.5 & 0 & 0 & 5 & 18.5 \\
\hline Intussusception & 2 & 7.4 & 0 & 0 & 2 & 7.4 \\
\hline Duodenal duplication cyst & 0 & 0 & 1 & 3.7 & 1 & 3.7 \\
\hline Mesenteric cyst & 1 & 3.7 & 0 & 0 & 1 & 3.7 \\
\hline Meckel's diverticulum & 1 & 3.7 & 1 & 3.7 & 2 & 7.4 \\
\hline Malrotation & 0 & 0 & 1 & 3.7 & 1 & 3.7 \\
\hline Obstructed Inguinal hernia & 1 & 3.7 & 0 & 0 & 1 & 3.7 \\
\hline Total & 21 & 77.77 & 6 & 22.22 & 27 & 100 \\
\hline
\end{tabular}

Table 3: Presentation of intestinal obstruction in age group 1-5 years $(n=17)$.

\begin{tabular}{|lllllll|}
\hline Etiology & Males & $\%(\mathbf{M})$ & Females & $\%(\mathbf{F})$ & Total & Total $(\%)$ \\
\hline Hirschsprung's disease & 11 & 64.7 & 0 & 0 & 11 & 64.70 \\
\hline Low ARM & 2 & 11.76 & 0 & 0 & 2 & 11.76 \\
\hline Neoplasm & 0 & 0 & 2 & 11.76 & 2 & 11.76 \\
\hline Unknown cause & 2 & 11.76 & 0 & 0 & 2 & 11.76 \\
\hline Total & 15 & 88.23 & 2 & 11.76 & 17 & 100 \\
\hline
\end{tabular}

Table 4: Etiology of intestinal obstruction in 5-14 years $(n=14)$.

\begin{tabular}{|lllllll|}
\hline Etiology & Males & $\%(\mathbf{M})$ & Females & $\%(\mathbf{F})$ & Total & Total $(\%)$ \\
\hline Hirschprung ds & 2 & 14.28 & 0 & 0 & 2 & 14.28 \\
\hline Tuberculosis & 2 & 14.28 & 4 & 28.56 & 6 & 42.85 \\
\hline Neoplasm & 0 & 0 & 1 & 14.28 & 1 & 7.14 \\
\hline Unknown cause & 4 & 28.56 & 1 & 14.28 & 5 & 35.71 \\
\hline Total & 8 & 57.14 & 6 & 42.85 & 14 & 100 \\
\hline
\end{tabular}

Table 5: According to term pregnancy $(n=128)$.

\begin{tabular}{|lll|}
\hline Pregnancy & No. of Cases & $\%$ \\
\hline Term & 122 & 95.32 \\
\hline Preterm & 6 & 4.68 \\
\hline Total & 128 & 100 \\
\hline
\end{tabular}


Table 6: According to site of delivery $(n=128)$.

\begin{tabular}{|lll|}
\hline Site of Delivery & No. of Cases & $\%$ \\
\hline Home & 96 & 75 \\
\hline Hospital & 32 & 25 \\
\hline Total & 128 & 100 \\
\hline
\end{tabular}

Table 7: According to finding of antenatal USG $(n=128)$.

\begin{tabular}{|lll|}
\hline Finding of antenatal USG & No. of Cases & $\%$ \\
\hline Normal & 67 & 52.34 \\
\hline Polyhydramnios & 5 & 3.9 \\
\hline Not done & 56 & 43.76 \\
\hline Total & 128 & 100 \\
\hline
\end{tabular}

Table 8: Presenting symptoms $(n=128)$.

\begin{tabular}{|lll|}
\hline Symptoms & No. of cases & $\%$ \\
\hline Not passing stool & 120 & 93.75 \\
\hline Distension of abdomen & 116 & 90.63 \\
\hline Absent or abnormal anal opening & 66 & 51.56 \\
\hline Vomiting-non bilious & 79 & 61.71 \\
\hline Vomiting-bilious & 20 & 15.62 \\
\hline Pain abdomen & 37 & 28.90 \\
\hline Red currant jelly & 2 & 1.5 \\
\hline
\end{tabular}

Table 9: According to type of presentation $(n=128)$.

\begin{tabular}{|lll|}
\hline Presentation & No. of cases & $\%$ \\
\hline Acute & 93 & 72.66 \\
\hline Chronic & 35 & 27.34 \\
\hline Total & 128 & 100 \\
\hline
\end{tabular}

Table 10: According to type of etiology $(n=128)$.

\begin{tabular}{|lll|}
\hline Etiology & No. of cases & $\%$ \\
\hline Congenital & 110 & 85.94 \\
\hline Acquired & 18 & 14.06 \\
\hline Total & 128 & 100 \\
\hline
\end{tabular}

\section{DISCUSSION}

In our study maximum patients of Intestinal Obstruction are of neonatal age group and followed by 1 month to 1 year. Same type of results were found in study by Ogundoyin OO et al, (61.46\% in less than 1 year age), Soomro BA et al, (37.3\% in less than 1 year age), Ratan SR et al, (72\% in less than 1 year age). ${ }^{9-11}$ Most of our cases are neonates in both the sex. Sex ratio in our study is $2.5: 1(\mathrm{M}: \mathrm{F})$.It is comparable with study done by Sirajuddin et al, Soomro BA et al and Ogundoyin et al. ${ }^{9,10,12}$

Current study hospital is tertiary referral center, most of our cases were neonates and small children (less than 1 yr) referred from other centers for the management, thats why most of our cases had congenital anomaly like ARM and Hirschsprung's disease. ARM and Hirschsprung's disease was found in large number in study done by Ogundoyin OO et al, 2009 (36.16\%). ${ }^{9}$ In many other studies their cases were of older age, so common causes in their study were intussusceptions. Among neonates ARM $(81.42 \%)$ is the most common cause of intestinal obstruction followed by G.I. Atresias (7.13\%) and Hirschsprung's disease (5.7\%).

Saha et al also found ARM (35\%) as a most common cause of G.I. obstruction followed by Hirschsprung's disease $(22.9 \%) .{ }^{13}$ In our institute cases of Hirschsprung's disease were presented later in age of 1 month-1 yr, so incidence of Hirschsprung's disease is less in neonates. IHPS and Hirschsprung's disease are most common 
cause of intestinal obstruction in 1 month to 1 year age group in our study. During 1 to 5 years age group Hirschsprung's disease is our very common cause of intestinal obstruction. Soomro BA et al also found maximum number of patients of Hirschsprung's disease in this age group. ${ }^{10}$

In our study Tuberculosis and other inflammatory pathology is a common cause during 5-14 years age period and same findings are there in other studies. In our study most of deliveries were term and at home. Only in $3.9 \%$ deliveries had history of polyhydramnios. Most of our neonatal causes were ARM and Hirschsprung's disease and these diseases don't cause polyhydramnios. G.I. Atresia is very less $(3.9 \%)$ in our study which is one common G.I. cause for polyhydramnios and prematurity.

In our study most common presenting symptom was not passing stool in all age group.

In our study not passing stool was found in $93.75 \%$ cases followed by distension of abdomen in 90.6\%. This correlates with the studies by Ogundoyin et al, and Sirajuddin et al. ${ }^{9,12}$

\section{CONCLUSION}

Present study concludes that congenital causes are more common in paediatric intestinal obstruction cases. Early diagnosis and intervention (with dedicated surgical care) are crucial factors to arrest disease process and improving the outcome. The finding of the present study will be helpful for surgeons by giving idea of most common aetiologies in this area, as very few studies available.

\section{ACKNOWLEDGEMENTS}

The authors are thankful to all the faculty and technical staff of department of Surgery, Dr. BRAM Hospital, Pt. J. N. M. medical college, Raipur (C.G.) India, for their cooperation and support during the entire study period.

\section{Funding: No funding sources}

Conflict of interest: None declared

Ethical approval: The study was approved by the Institutional Ethics Committee

\section{REFERENCES}

1. Evers BM, Beauchamp RD, Evers BM, Mattox KL. Small Intestine. In: Sabiston's biological basis of modern surgical practice. $19^{\text {th }}$ edition, Durham, David Sabiston; 2012:1334.

2. Millar AJW, Rode H, Cywes S, Murphy JP, Sharp RJ, Sigalet DL, et al. Intestinal atresia and Stenosis. In: Aschcraft's paediatric surgery. $6^{\text {th }}$ edition, Philadelphia, W.B. Saunders company; 2014:40625.

3. Clark LA, Oldham KT, Murphy JP, Sharp RJ, Sigalet DL, et at. Malrotation. In: Aschcraft's paediatric surgery. $6^{\text {th }}$ edition, Philadelphia, W.B. Saunders company; 2014:425-35.

4. Decker GAG, Dlessis DJ. The Duodenum, jejunum, ileum and large bowel. In: Lee McGregor's synopsis of surgical anatomy $12^{\text {th }}$ ed. Bombay, Varghese Publishing House; 1999:22-41.

5. Schumpelick V, Dreuw B, Ophoff K. Appendix and caecum. In Surg Clin N Am. 2000:295-315.

6. Ganong WF. Regulation of gastrointestinal functions. William F Ganong's Review of Medical Physiology. $25^{\text {th }}$ ed. Singapore, McGraw Hill; 2015: 605-60.

7. Fallat ME, Murphy JP, Sharp RJ, Sigalet DL. Intussusception. In: Aschcraft's paediatric surgery, $6^{\text {th }}$ edition, Philadelphia, W.B. Saunders company; 2014:518-27.

8. Das S. Intestinal Obstruction: a concise textbook of surgery. $6^{\text {th }}$ ed. Calcutta; 2008:1002-14.

9. Ogundoyin OO, Afolabi AO, Ogunlana DI, Lawal TA, Yifieyeh AC. On Pattern and outcome of childhood intestinal obstruction at a tertiary hospital in Nigeria; African H S. 2009;9(3);170-3.

10. Soomro BA, Kella N, Memon GA, Siddiqui MA. Pattern of intestinal obstruction in infants and children. Pak J Med Sci. 2011;27(5):1009-13.

11. Ratan SR, Rattan KN, Pandey RM, Sehgal T, Kumar A, Ratan J. Surgically treated intestinal obstruction in children, causes and implications. In Ind J Gastroenterol. 2006;25:320-2.

12. Somroo $\mathrm{S}$, Mughal SA. Intestinal obstruction in children. J of Surg Pak. 2013;18:20-3.

13. Saha AK, Ali MB, Biswas SK, Sharif HMZ, Azim A. Neonatal intestinal obstruction: Pattern, problems and outcome. Bang Med J (Khulna). 2012;45;6-10.

Cite this article as: Memon AM, Patel JL, Siddharth RK, Dhuware MK. A study on clinico etiological spectrum of intestinal obstruction in paediatric age group. Int J Res Med Sci 2016;4: 3153-8. 